Military Technical College Kobry El-Kobbah

Cairo, Egypt

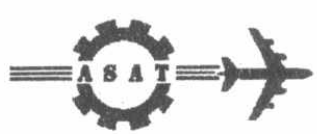

$10^{\text {th }}$ International Conference

On Aerospace Sciences\&

Aviation Technology

\title{
EXPERIMENTAL STUDY OF LAB-SCALE HTPB/GOX HYBRID ROCKET MOTOR
}

\author{
HOSAM, ${ }^{*}$ E. M.
}

\begin{abstract}
:
The presented paper introduces main results obtained during the course of static tests carried out for reaching a proper design of testing hybrid motor using several compositions of hydroxy terminated polybutadiene (HTPB) fuel binder and some additives with gaseous oxygen as an oxidizer.

The results of preliminary experiments for testing motor design are presented. Investigation on the methods of enhancing the regression rate for the HTPB fuel used in HTPB/GOX testing hybrid motor is presented. The effect of the addition of Ammonium Perchlorate (AP) and aluminum (Al) to the fuel binder was also taken into consideration.
\end{abstract}

\section{NOMENCLATURE}

$\begin{array}{ll}\text { DBTL } & \text { Dibutyl tin dilaurate } \\ \text { GOX } & \text { Gaseous oxygen } \\ \text { HPRM } & \text { Hybrid propellant rocket motor } \\ \text { HTPB } & \text { Hydroxy terminated Polybutadiene } \\ \text { TMP } & \text { Tri methyl propane } \\ \text { IPDI } & \text { Isophorone diisocyanate } \\ \text { CC } & \text { Combustion chamber } \\ p_{m} & \text { Mean pressure in combustion chamber } \\ t_{T} & \text { Total time of operation }\end{array}$

- Egyptian Armed Forces, MTC, Cairo - Egypt. 


\section{INTRODUCTION}

The long term and ultimate goal of this experimental work is to develop a flight test concept of hybrid rocket motor through a series of Lab-scale hybrid rocket motor tests, being determined for demonstration of the inherent system safety, flexibility, reliability, and lower cost for a flight application. Other objective of this work is to investigate internal ballistics, performance characteristics, fuel regression parameters, and measurement accuracy. To achieve that goal, an understanding of the essential design parameters and acquisition of the necessary data to optimize a flight system were required. A series of static tests were carried out to gain the experience and the data necessary to develop flight concept of hybrid rocket motor. Gaseous oxygen was selected as an oxidizer with HTPB fuel grain in the presupposed tested HPRM to avoid the expected problems related to liquid oxygen and sensitivity to injector design [1]. It was therefore possible to complete a number of tests to acquire the necessary data to validate the burn rate model for polyurethane fuels (HTPB).

The dependence of solid fuel regression rate on various operating conditions is one of the most important design aspects in the course of experimental study of hybrid motors. The primary objectives of the first part of the preliminary tests were to reach a suitable construction of the testing motor. In addition, the presupposed construction of the testing rocket motor must secure a good compatibility, then to perform a system checkout of all pressure lines, valves, and fittings and to test the ignitability of the supposed coupling of HTPB with a steady flow of GOX. For investigation of the hybrid propulsion system, two main test series were carried out in order to investigate some of the important aspects of the hybrid rocket design (see table 1).

Table 1.

\begin{tabular}{|c|c|}
\hline Test series & Objectives \\
\hline $\begin{array}{l}\text { Preliminary } \\
\text { experiments }\end{array}$ & $\begin{array}{l}\text { - Preparation of Fuel binder samples } \\
\text { - Test of the rocket motor components } \\
\text { - Ignition behavior } \\
\text { - Firing tests for HPRM of HTPB fuel grain } \\
\text { - Determination of best operating conditions }\end{array}$ \\
\hline Firing tests & $\begin{array}{l}\text { Test of the entire propulsion system, three } \\
\text { series of testing motors with: } \\
\text { - Pure HTPB fuel grain } \\
\text { - HTPB + AP fuel grain } \\
\text { - HTPB + Al fuel grain }\end{array}$ \\
\hline
\end{tabular}

\section{PREPARATION OF FUEL BINDER GRAINS}

The solid fuel composition was mainly from HTPB. A small amount of DBTL catalyst was mixed with the fuel. In addition, trimethyl propane (TMP) was added to improve the mechanical properties of the grain; for curing Isophorone diisocyanate (IPDI) was used. 
The preparation of the fuel grain was as follows, the premix containing HTPB prepolymer (see table 2), and TMP triol was thoroughly mixed for 10 minutes. Then, adding the presupposed quantity of AP or Al (according to the needed formulation) and finally on adding IPDI the blend was mixed for a further 10 minutes [2].

Table 2.

\begin{tabular}{|c|c|}
\hline Reduced summary formula & $\mathrm{HO}-\mathrm{C}_{3} \mathrm{H}_{6}-\left(\mathrm{C}_{4} \mathrm{H}_{6}\right)_{\mathrm{n}(50-58)}-\mathrm{C}_{3} \mathrm{H}_{6}-\mathrm{OH}$ \\
\hline Functional group & $-\mathrm{OH}$ \\
\hline Number of OH- group per gram & $3.0-3.3 \mathrm{~m} \mathrm{~mole} / \mathrm{g}$ \\
\hline Viscosity $\left(38^{\circ} \mathrm{C}\right)$ & $20-25 \mathrm{~Pa} . \mathrm{s}$ \\
\hline Density $\left(20^{\circ} \mathrm{C}\right)$ & $990 \mathrm{~kg} / \mathrm{m}^{3}$ \\
\hline
\end{tabular}

Then, the mixture was poured into the prepared combustion chamber lined with two layers of $2.10^{-3} \mathrm{~m}$ thick HTPB rubber based insulator according to the predetermined grain dimensions (see Fig. 1) and cured, first for three days at room temperature and then for four days at $60 \mathrm{C}$. For evaluation of the prepared HTPB fuel binder samples, some tests for mechanical properties of the samples must be carried out to be sure that the prepared samples withstand the whole combustion conditions. The percentage mass composition of the base fuel was as in table 3 .

\section{Table 3.}

\begin{tabular}{|c|c|c|c|c|}
\hline $\begin{array}{c}\text { Component } \\
\text { (\%) }\end{array}$ & $\begin{array}{c}\text { Pure } \\
\text { HTPB }\end{array}$ & $\begin{array}{c}\text { HTPB + 5 \% } \\
\text { AP }\end{array}$ & $\begin{array}{c}\text { HTPB + 15 \% } \\
\text { AP }\end{array}$ & $\begin{array}{c}\text { HTPB + 15\% } \\
\text { Al }\end{array}$ \\
\hline $\begin{array}{c}\text { HTPB } \\
\text { prepolymer }\end{array}$ & 96 & 91 & 81 & 81 \\
\hline TMP triol & 3.4 & 3.4 & 3.4 & 3.4 \\
\hline $\begin{array}{c}\text { IPDI curing } \\
\text { agent }\end{array}$ & 0.5 & 0.5 & 0.5 & 0.5 \\
\hline DBTL catalyst & 0.1 & 0.1 & 0.1 & 0.1 \\
\hline AP & - & 5 & 15 & - \\
\hline Al & - & - & - & 15 \\
\hline
\end{tabular}

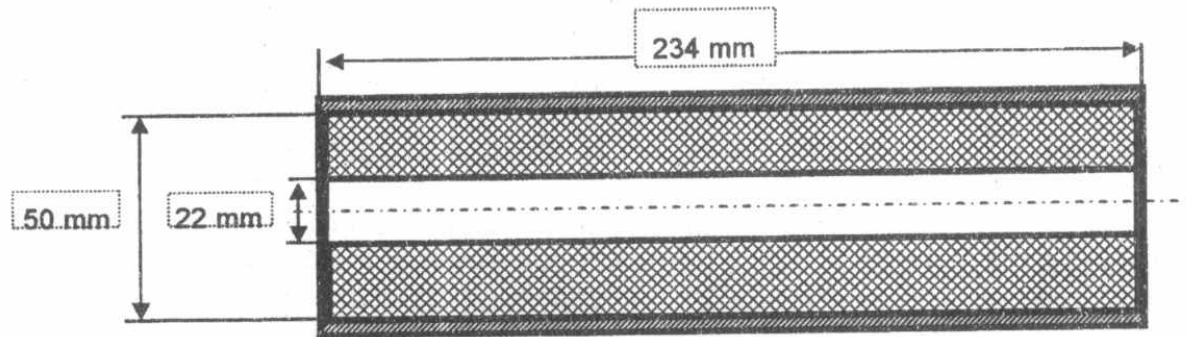

Fig. 1. Dimensions of HTPB Grain inside HPRM Combustion Chamber 


\section{COMPONENTS OF THE TESTING MOTOR}

The static test hybrid motor consists of a fuel section, contained within a steel combustion chamber, with a high-pressure source of gaseous oxygen to support combustion and source of gaseous nitrogen for quenching the combustion at the end of the burning operation. Accurate pressure gauges and a special flow meter for adjustment of the flow rate [1] can regulate both of them.

The motor components include (see Fig. 2) a head of the testing motor, which contains four openings; one for the combustion chamber, one opening for igniter, one for front pressure transducer and last one for either the injection of gaseous oxygen in case of combustion or injection of gaseous nitrogen in case of quenching [3], [4].

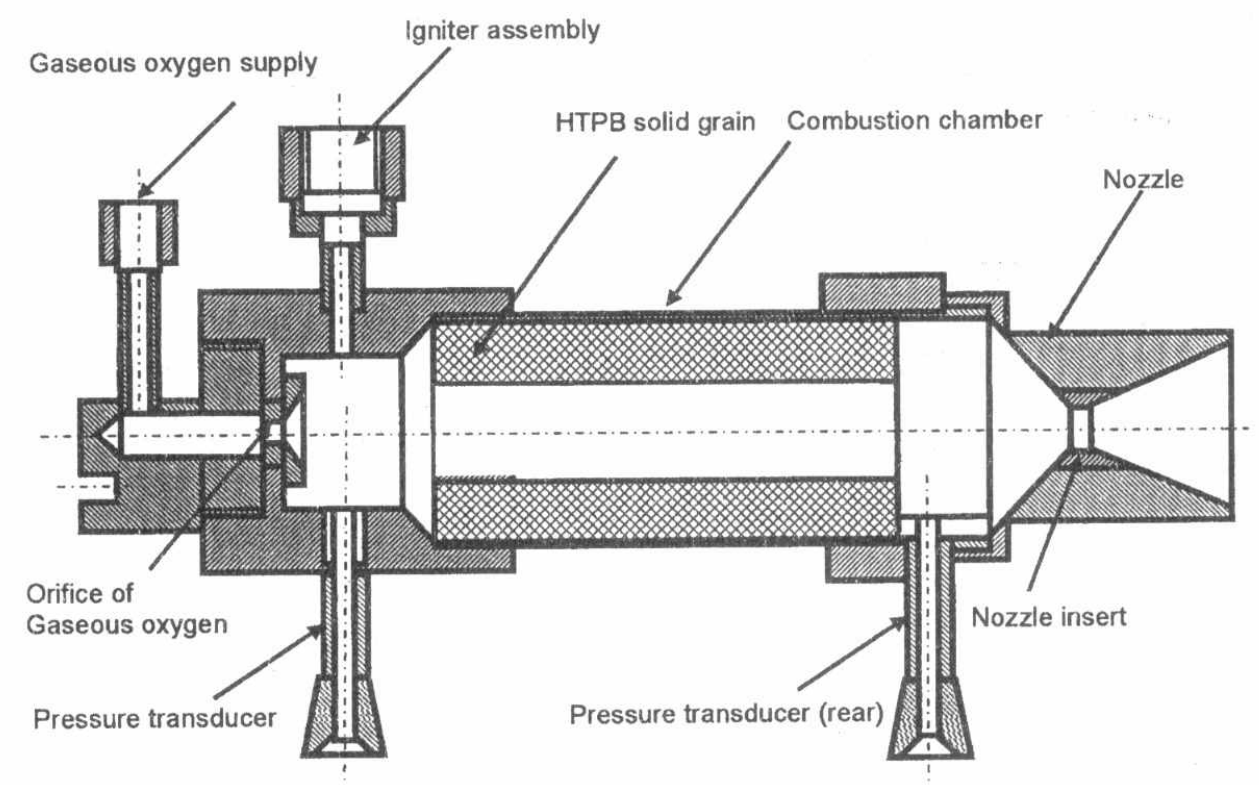

Fig. 2. Scheme of the Prepared HPR Testing Motor

Scheme of the testing motor is introduced in Fig. 2. HTPB fuel binder grain is directly cast inside the combustion chamber, (at the beginning) not to the full length of the chamber. Empty part of the combustion chamber is used as an auxiliary chamber, which secures a good turbulent mixing of the gaseous oxygen and the decomposition products of HTPB fuel binder.

Such testing motors use a normal geometric nozzle with required critical diameter. Sometimes HTPB fuel binder is cast inside in a full length of the combustion chamber. In this case, nozzles with special insert (molybdenum) must be used to withstand the excessive high velocity and temperature of the produced gases during combustion. 
Each test run included the following steps. By suitable setting of the oxygen ball valve opening, constant supply pressure of the GOX was maintained upstream of the sonic nozzle. After the flow became steady, the igniter was initiated. After the desired time of burning quick GOX supply shut off followed by nitrogen purge to extinguish the combustion.

Thrust and the pressures were measured upstream and downstream of sonic nozzle. All signals from strain gauge type thrust and pressure - transducers were recorded using LabVIEW program based on the data acquisition system.

\section{PRELIMINARY TESTS FOR THE PRESUPPOSED HPRM DESIGN}

Main objective of such preliminary test series is to examine the compatibility of all parts of the testing motor and to achieve normal burning without interruption. Success in the following tests will give the chance to examine a number of factors, which may affect the HPRM operation.

First test (No. 008) used HTPB fuel binder grain directly cast into the combustion chamber and not to the full length of the combustion chamber (see Fig. 3).

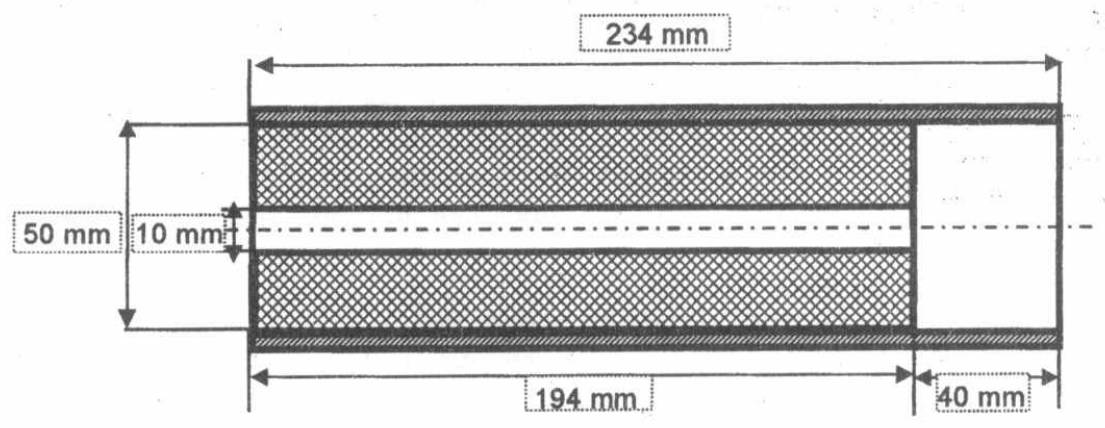

Fig. 3. Dimensions of HTPB Grain inside HM Combustion Chamber

The mass flow rate of oxygen was nearly the maximum possible flow rate $(\sim 30$ $1 / \mathrm{sec}$ ), which can be achieved by a special part with an orifice having certain diameter. Normal metallic nozzle was used with a critical diameter equal to $5.4 .10^{-3} \mathrm{~m}$. The conclusion from the following test is:

- Non homogenous burning;

- Nozzle destruction at the end of operation;

- HTPB fuel grain after burning has some wavy shape;

- Combustion chamber pressure and thrust seems to be very high (no records). 
From obtained results it was clear that, normal steel nozzle is not suitable for such a test because of very high temperature and velocity of produced gases. In addition, possible to think about new dimensions of the grain, in parallel with decreasing of the oxygen mass flow rate to achieve a normal burning.

Second test (No. 009) was carried out on the same way like in the test No. 008 but with a new dimensions of the fuel grain (port diameter is $0.022 \mathrm{~m}$, see Fig. 1). In addition, a special steel nozzle with molybdenum insert to withstand the excessive high temperature and velocity of gases was used. In this test the oxygen flow rate was about only $10 \%$ from the value of oxygen flow rate used in the test No. 008 (narrower orifice of oxygen flow). The blowing of gaseous oxygen was only for 4 seconds to avoid excessive stresses on the nozzle critical section directly followed by blowing of gaseous nitrogen for quenching of the combustion. The critical diameter of the nozzle was $7.10^{-3} \mathrm{~m}$. The conclusion from the following test is:

$>$ Homogenous buming;

$>$ Nozzle part was very hot at the end of operation;

HTPB fuel grain after burning was smooth with a uniform web thickness;

$>$ Combustion chamber pressure $p=1.56 \mathrm{MPa}$, thrust seems to be very low.

It is clear that the normal burning is achieved but thrust was very weak. Therefore was performed another test where the change of mass flow rate of oxygen was assumed.

Third test (No. 010) was carried out on the same way like in the test No. 009, but with oxygen flow rate about only twice the value used in the test No. 009 (wider orifice of oxygen flow). Blowing of gaseous nitrogen for quenching of the combustion directly followed the blowing of gaseous oxygen. The conclusion from this test is:

$\checkmark$ Homogenous burning;

$\checkmark$ Nozzle part was very hot at the end of operation;

$\checkmark$ HTPB fuel grain after burning was smooth with a uniform web thickness (smaller than that in test No. 009);

$\checkmark$ Combustion chamber pressure $p=1.67 \mathrm{MPa}$ and thrust $F=98 \mathrm{~N}$ (slightly increases during the course of burning, progressive).

It is clear that the normal burning is achieved and a nominal value thrust, too.

\section{FIRING TESTS FOR DIFFERENT HP COMPOSITIONS}

Success in the preliminary experiments using the presupposed design of testing hybrid motor give the chance to examine different HP compositions containing some additives, e.g. $\underline{A P}$ and $\underline{A l}$. It is necessary to keep the same construction of the testing motor (critical diameter of nozzle, dimensions of $\mathrm{CC}$ ) and to keep dimensions of the fuel 
grain. Four testing series were prepared, each one of them consists of 4 firing tests in order to examine different fuel binder compositions:

$\checkmark$ Pure HTPB fuel binder;

- HTPB + $5 \% A P$;

$H T P B+15 \% A P$.

○ HTPB + $15 \%$ Al.

Composition of the fuel binder for each shot (see table. 3 ) is expected to affect the regression rate of the fuel binder, possible to obtain such effect by investigating the mean pressure inside the combustion chamber through the time of total operation. Results of the static firing tests (table 4) collect the values of mean pressure and total time of operation for each test.

Table 4.

\begin{tabular}{|c|c|c|c|c|c|c|c|c|c|c|c|c|}
\hline \multirow[b]{2}{*}{$\begin{array}{l}\text { Test } \\
\text { No. }\end{array}$} & \multirow[b]{2}{*}{$\begin{array}{l}\text { Shot } \\
\text { No. }\end{array}$} & \multicolumn{2}{|c|}{ Pure HTPB } & \multirow[b]{2}{*}{$\begin{array}{l}\text { Shot } \\
\text { No. }\end{array}$} & \multicolumn{2}{|c|}{$\mathrm{HTPB}+5 \% \mathrm{AP}$} & \multirow[b]{2}{*}{$\begin{array}{l}\text { Shot } \\
\text { No. }\end{array}$} & \multicolumn{2}{|c|}{ HTPB $+15 \%$ AP } & \multirow[b]{2}{*}{$\begin{array}{l}\text { Shot } \\
\text { No. }\end{array}$} & \multicolumn{2}{|c|}{ HTPB $+15 \%$ Al } \\
\hline & & $\begin{array}{l}\mathrm{P}_{\mathrm{m}} \\
(\mathrm{MPa})\end{array}$ & $\begin{array}{l}t_{T} \\
\text { (s) }\end{array}$ & & $\begin{array}{c}\mathrm{p}_{\mathrm{m}} \\
(\mathrm{MPa})\end{array}$ & $\begin{array}{l}t_{T} \\
(s)\end{array}$ & & $\begin{array}{l}\mathrm{P}_{\mathrm{m}} \\
(\mathrm{MPa})\end{array}$ & $\begin{array}{l}t_{T} \\
(s)\end{array}$ & & $\begin{array}{c}\mathrm{P}_{\mathrm{m}} \\
(\mathrm{MPa})\end{array}$ & $\begin{array}{l}t_{T} \\
(s)\end{array}$ \\
\hline 1 & $\begin{array}{c}\text { HRK- } \\
16\end{array}$ & 2.07 & 4.50 & $\begin{array}{l}\text { HRK- } \\
22\end{array}$ & 1.976 & 3.39 & $\begin{array}{c}\text { HRK- } \\
23\end{array}$ & 1.986 & 4.04 & $\begin{array}{l}\text { HRK- } \\
52\end{array}$ & 1.736 & 4.29 \\
\hline 2 & $\begin{array}{c}\text { HRK- } \\
17\end{array}$ & 1,553 & 4.37 & $\begin{array}{l}\text { HRK- } \\
24\end{array}$ & 1.765 & 4.04 & $\begin{array}{l}\text { HRK- } \\
25\end{array}$ & 1.906 & 5.66 & $\begin{array}{c}\text { HRK- } \\
53\end{array}$ & 1.689 & 4.68 \\
\hline 3 & $\begin{array}{c}\text { HRK- } \\
18\end{array}$ & 1.482 & 4.83 & $\begin{array}{c}\text { HRK- } \\
26\end{array}$ & 1.623 & 5.17 & $\begin{array}{l}\text { HRK- } \\
27\end{array}$ & 1.835 & 5.33 & $\begin{array}{c}\text { HRK- } \\
54\end{array}$ & 1.581 & 4.93 \\
\hline 4 & $\begin{array}{c}\text { HRK- } \\
19\end{array}$ & 1.472 & 5.06 & $\begin{array}{c}\text { HRK- } \\
28\end{array}$ & 1.628 & 4.61 & $\begin{array}{c}\text { HRK- } \\
29\end{array}$ & 1.714 & 4.69 & $\begin{array}{l}\text { HRK- } \\
55\end{array}$ & 1.574 & 5.70 \\
\hline Mean & & 1.502 & 4.753 & & 1.748 & 4.278 & & 1.860 & 4.93 & & 1.645 & 4.90 \\
\hline
\end{tabular}

Remark: The result of static test HRK-16 has been carried out for little different conditions from the other static test, therefore this result is rejected for determination of mean value and respective dispersion. In this state of experiments, such conclusion is possible, because this result will not influence the final set of firing tests.

Fig. 4 represents real pressure-time diagrams being obtained during this stage of firing tests. From introduced results, it is evident that there is some difference between pure HTPB and the remaining compositions, i.e. HTPB + additives.

In case of $\mathrm{HTPB}+5 \%$ AP the mean value of chamber pressure rises about $16 \%$. In case of $\mathrm{HTPB}+15 \% \mathrm{AP}$ the pressure rises about $24 \%$. Comparing the variants of $\mathrm{AP}$ addition (i.e. $5 \%$ and $15 \%$ of AP) the pressure rise is about $6 \%$.

Regarding the time of HPRM testing operation, the mentioned influence is as follows; when adding $5 \%$ of AP the time of operation (total) is less by about $10 \%$, meanwhile in case of $15 \%$ AP addition will be greater about $4 \%$. Comparing the variants of AP addition there exist some time prolongation about $13 \%$. 
The influence of Al addition to the pure HTPB fuel could be evaluated completely by the chamber pressure average value, which in this case rises about $10 \%$. Regarding the total time of testing HPRM, there exist some time prolongation about $3 \%$.
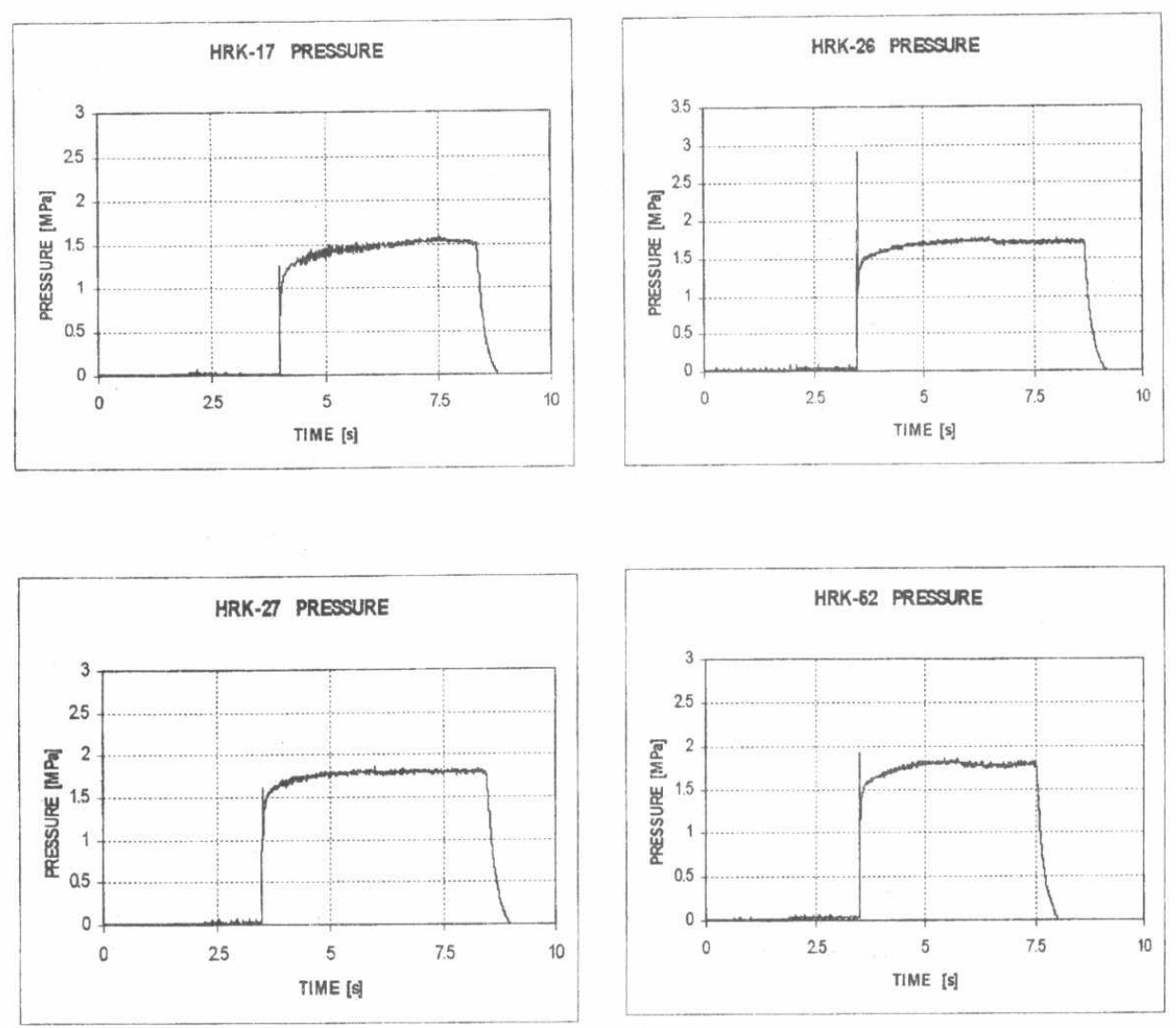

Fig. 4. Pressure-time curves of some firing tests

\section{CONCLUSION}

Introduced testing hybrid rocket motor is suitable for studying various factors, which may affect the hybrid motor during its operation. In addition, such scheme of testing motor is simple and gives a chance for more investigation of hybrid rocket problems. 
Evaluating the existing information from preliminary firing tests show that, the utilization of pure HTPB as solid fuel for HPRM is possible and for experimental measurements very useful with convenient safety.

The introduction of $5 \%$ AP into the HTPB fuel grain increase the value of mean pressure inside the CC by about $16 \%$ when compared with pure HTPB fuel grain. Introduction of $15 \%$ AP into the HTPB fuel grain increase such value of the mean pressure inside the CC by about $24 \%$ more than that of pure HTPB fuel binder.

For both AP content in the HTPB grain, such enhancement of the mean pressure inside the testing motor $C C$ is due to exothermal increase of heat due to the violent reaction between the evolved ammonia and perchloric acid from AP decomposition with purged oxygen. That means, addition of $A P$ is able to enhance the regression rate at high mass flux conditions, when oxygen is available closer to the fuel surface to be in contact with the decomposed fuel vapour and $A P$ decomposition products in a turbulent mixture. I.e. AP particles in the fuel grain are additional heat source resulting from such turbulent flow across the flame front at high mass flux conditions.

Introduction of about $15 \%$ of $A$ l into the fuel grain enhances the value of mean pressure inside CC about $10 \%$. Mainly due to the radiation heat transfer by Al particles. In such a case HTPB fuel grain with Al will obey pressure dependent burning rate model and such a high radiation heat transfer component would perhaps lead to higher regression rate.

Finally, the performed static firing tests were successful and the obtained results are real and near to those being introduced in available references. Therefore, the described way of solution of main topics promises convenient results for final stage of firing test leading to burning law definition.

\section{REFERENCES}

[1] MARTIN J. ; CHIAVERINI; KENNETH KUO and K. ARIE PERETZ: "Regression Rate and Heat Transfer Correlation for HTPB/GOX Combustion in a Hybrid Motor" Department of Mechanical Engineering-Pennsylvania State University, PA16802, 1998.

[2] PHILMON G.; KRISHNAN S. ; VARKEY P. M. ; RAVINDRAN M. and RAMACHANDRAN L.: "Fuel Regression Enhancement Studies in HTPB/GOX Hybrid Rocket Motors", Indian Institute of Technology Madras, Vikram Sarabhai Space Center-India, AIAA 98-3188, 1998.

[3] MATTHIAS GROSSE: "Development Work on a Small Experimental Hybrid Rocket" Buck Werke \& Co, Bad Reichenhall-Germany, 1997.

[4] CHIAVERINI M. J.; SERIN Y. C. and KENNETH KUO: "Thermal Pyrolysis and Combustion of HTPB-Based Solid Fuels for Hybrid Rocket Motor Applications" Department of Mechanical Engineering, Pennsylvania State University, AIAA, 1996. 